\title{
Surface Thermodynamics of Hydrocarbon Vapors and Carbon Dioxide Adsorption on Shales
}

Xu Tang ${ }^{1,2}$

1 School of Chemistry, University of Nottingham, Nottingham, NG7 2RD, UK;

2 Key Laboratory of Petroleum Resources Research, Institute of Geology and Geophysics, Chinese Academy of Sciences, Beijing 100029, China

Corresponding author: Xu Tang (xutang2050@outlook.com)

\section{Highlights:}

Hydrocarbon vapor and carbon dioxide adsorption models on shales are validated.

Intrinsic thermodynamic potentials of vapor adsorption on shales are calculated.

Isosteric enthalpy and entropy shows temperature-dependent behavior.

Isosteric enthalpy and entropy positively correlate to vapor molecular mass.

Abstract: Understanding hydrocarbon vapors and carbon dioxide adsorption mechanism on shales lays the foundation for in situ hydrocarbon resource estimation and enhanced hydrocarbon recovery via carbon dioxide injection. However, surface thermodynamic potentials of hydrocarbon vapor and carbon dioxide adsorption on shales have rarely been reported. This work develops a rigorous framework for direct description of hydrocarbon vapors and carbon dioxide adsorption isotherms on shales and for straightforward calculation of the intrinsic thermodynamic potentials by considering non-ideal gas behavior. On the basis of the Langmuir adsorption model, the maximum adsorption capacity of methane, ethane, propane, n-butane, iso-butane and carbon dioxide adsorption on shales positively correlates to each gas' molecular mass. Carbon dioxide adsorption capacity is higher than methane and ethane but is lower than propane, n-butane and iso-butane. According to the generalized multilayer adsorption model, the monolayer adsorption capacity of $n$-hexane is slightly higher than that of $n$-heptane due to the small molecular diameter of $n$-hexane. The temperature-dependent behavior of isosteric enthalpy and entropy for these vapors is attributed to their non-ideal gas behavior and the temperaturedependent adsorption uptakes. Isosteric enthalpy and entropy in general positively correlate to the molecular mass of vapors. Isosteric enthalpy and entropy of carbon dioxide and propane are almost identical in behavior given that their molecular masses are very close. Isosteric enthalpy and entropy of iso-butane are lower than that of n-butane due to their molecule polarity difference. The shale selectivity of propane, n-butane and isobutane is higher than carbon dioxide while the shale selectivity of methane and ethane is lower than carbon dioxide. These surface thermodynamic characteristics therefore provide new perspectives on understanding the interaction of hydrocarbon vapors/carbon dioxide and shales for enhanced hydrocarbon recovery via carbon dioxide injection.

Key works: Shale, Hydrocarbon vapor, Adsorption, Enthalpy, Entropy

Tang, X. (2018) Surface Thermodynamics of Hydrocarbon Vapors and Carbon Dioxide Adsorption on Shales. Fuel. https://doi.org/10.1016/..fuel.2018.10.034. 
43 The application of hydraulic fracturing and horizontal drilling unlocks hydrocarbon resources in low permeability shale formations around the world and revolutionizes the world energy supply chain (1-3). Natural gas production from unconventional shale reservoirs has been a primary focus of energy companies in North America over the past decades. Natural gas produced from subsurface shale formations can be generally grouped into dry natural gas and wet natural gas (4-5). Dry natural gas is composed of mostly methane $(\mathrm{CH} 4)$, and wet natural gas contains methane and a descent amount of natural gas liquids (NGLs). The NGLs are hydrocarbon mixtures of ethane (C2H6), propane $(\mathrm{C} 3 \mathrm{H} 8)$, $\mathrm{n}$-butane $(\mathrm{nC} 4 \mathrm{H} 10)$, isobutane (isoC4H10), and natural gasoline (known as pentane $(\mathrm{C} 5 \mathrm{H} 12)$ and heavier hydrocarbons) (6). While NGLs are gaseous at subsurface reservoir conditions, they condense under atmosphere pressure and transform into liquids. NGLs are also central ingredients in many industrial processes like the petrochemical process, ethylene production, ethanol denaturing and fuel uses, which plays an essential role in most sectors of the economy (5-7). NGLs production therefore provides incentives to drill in liquids-rich shale reservoirs with significant NGLs content and also yields added benefits for shale gas development in major shale basins in North America.

Organic-rich shale is a complex natural material manifesting nanoscopic properties such as abundant nanopores and extremely low permeability (nanoDarcy), as well as complex compositions, including minerals and organic matter (8-12). These nanoscopic characteristics along with the high temperature and high pressure in situ reservoir conditions limit a realistic understanding of hydrocarbon fluid storage and transport mechanisms in shale formations. Previous studies argue that the phase behavior of hydrocarbons in a confined nanospace is different from the conventional equation of state (13-15). It has also been shown that a good history match for oil production from wells in the middle Bakken formation is obtained only after considering the fluid phase behavior in small pores (14). Therefore, a true understanding of hydrocarbon phase behavior in shales is important for developing new, enhanced hydrocarbon recovery technologies.

Adsorption is generally defined as the enrichment of molecules, atoms or ions in the vicinity of an interface. In the case of gas/solid systems, adsorption takes place in the vicinity of the solid surface and outside the solid structure (16-18). Adsorption is a consequence of surface energy and is generally classified as physical and chemical adsorption. The physical adsorption is the characteristic of weak of van der Waals forces and chemical adsorption is characteristic of covalent bonding covalent bonding (17). Gas adsorption approach, as a physical adsorption process, has been widely used for evaluating nanoconfinement effect on phase behavior, separating pure gas from mixtures as well as probing nanopore structure of porous media (16-23). This routinely used approach has been adopted by researchers in shale gas industry to understand hydrocarbon vapores and shales interaction. Butane adsorption and condensation behavior in shale and semectite clay were studied using NMR, which indicates that when the pore size and pressure satisfy the Kelvin equation and the surface is hydrophobic, both nanopores in kerogen and nano/micropores between clay crystals can provide storage for hydrocarbons (24-25). Adsorption isotherms of $n$-hexane and $n$-heptane on two retorted oil shales were measured to probe the surface area of the shale samples 
which indicates the internal surface area of both shales are relatively low (26). Sorption of methane, ethane, propane, butane, carbon dioxide and nitrogen on asphaltene shows that asphaltene is a swellable amorphous sorbent and it also has a comparable adsorption capacity of microporous carbon with specific surface area over $1000 \mathrm{~m}^{2} / \mathrm{g}$ (27). Sorption of methane, ethane, propane, butane, carbon dioxide and nitrogen on kerogen shows that these vapors not only adsorb on the surface of kerogen but also dissolve in kerogen itself, and the heat of enthalpy was studied using Clausius-Clapeyron relationship (28). Pore structure and surface properties of shales were characterized by octane and heptane through Zeta adsorption isotherms (29). Based on the assumption that an organic pore is hydrophobic and a mineral pore is hydrophilic, three vapors, water, hexane and nitrogen, were used to probe the surface area of different shales (30). Energetic effects of adsorption of heptane, heptene, octane, hexene and hexane on hard coal samples of different metamorphism were studied, which shows that hexane behaves differently than other hydrocarbons of longer chains which may represent micropore penetration (31). Adsorption properties of hydrocarbons (n-decane, methylcyclohexane and toluene) on clay minerals were investigated, which shows that the adsorption properties of $n$-decane, methyl cyclohexane and toluene are associated with the specific surface areas, the pore volumes of mesopores and equilibrium pressures (32). A n-alkane adsorption evaluation model was developed on the basis of $n$-decane adsorption data on shales, and this study reveals that the adsorbed and condensed amounts of $n$-decane are directly controlled by total pore volume provided maily by organic matters and pyrite and siderite in shales (33). $\mathrm{Ad} /$ desorption isotherms of various hydrocarbons and carbon dioxide on two shales were measured, which shows the significant adsorption hysteresis of ethane, propane, nbutane and iso-butane adsorption on shales and the hysteresis is more pronounced under high pressure conditions (34-35). Apart from these experimental studies, molecular dynamics simulation of adsorption was also used to study phase behave of hydrocarbon vapors on shale pores. The phase behavior of various hydrocarbons in nanopores was studied via an engineering density functional theory (DFT) combined with Peng Robinson equation of state, which shows that capillary condensation and hysteresis are more likely in heavier hydrocarbons, at lower temperatures and in smaller pores, and phase change always occurs below the critical temperature and saturation pressure (36). Grand canonical Monte Carlo (GCMC) simulation for $\mathrm{CH} 4$ and $\mathrm{nC} 4 \mathrm{H} 10$ mixture adsorption indicates that decreasing gas pressure accelerates $\mathrm{CH} 4$ desorption but enhances $\mathrm{nC} 4 \mathrm{H} 10$ adsorption, and $\mathrm{CO} 2$ injection has the capacity to enhance heavier hydrocarbon recovery (37). GCMC simulation combined with engineering DFT was also applied to study the effect of pressure, temperature, and nanopore sizes on the bubble/dew point and hysteresis of hydrocarbons in nanopores, and it was found that the dew point of pure confined fluids approaches bulk saturation point as pore size increases, but bubble point can be very different from bulk even for very large pores (38). These modeling insights were also validated by experimental data using differential scanning calorimetry, which indicates that as pore diameter decreases from 37.9 to $4.1 \mathrm{~nm}$, the bubble point increases by as much as $15 \mathrm{~K}$ above bulk until the observed supercritical state (39-40). A phase equilibrium model inside shales by considering capillary pressure and adsorption effects was developed, and the modeling results of hydrocarbon mixtures show that adsorption and capillary pressure can significantly change the bulk phase composition and its corresponding phase envelope (41). The heavier components are always preferentially adsorbed, the adsorption selectivity of heavier components is moderate at high pressure 
and low temperature compared to that at low pressure and high temperature, and the adsorption effects are stronger for the gas bulk phase region, leading to bigger changes in the gas phase composition and the shift of the dew point curve (41).

Even though previous studies advance our understanding about heavier hydrocarbons and shale interactions, some fundamental questions still remain unclear for the hydrocarbon vapor adsorption process in shales. First, current available adsorption models such as the classic Langmuir model and the multilayer adsorption model have rarely been employed to describe measured hydrocarbon vapors adsorption isotherms on shales. Even though high quality adsorption isotherm data were measured, quantitative analysis of these adsorption isotherms via adsorption models were not conducted (34-35). The lack of a suitable adsorption model makes it challenging to study the impact of shale material properties on hydrocarbon vapor adsorption behavior on shales quantitatively. Second, investigation of surface thermodynamic potentials such as enthalpy and entropy for hydrocarbon vapors and carbon dioxide on shales were rarely reported. The isosteric enthalpy of adsorption is historically estimated by applying the Clausius-Clapeyron (C-C) relationship to measured adsorption isotherm data, and the $\mathrm{C}-\mathrm{C}$ approach is based on the ideal gas law and ignores the contribution of the adsorbed phase (42-43). This means a non-ideal gas behavior cannot be considered using the C-C approach (44-45). The nonideal behavior of hydrocarbon vapors and carbon dioxide is presented via the compressibility factor $(Z)$, which is a function of temperature and pressure as shown in Figure 1. Even though an analytical approach has been developed for calculating the thermodynamic potentials of supercritical fluids and water vapor adsorption on shales and coal accurately (46-49), whether the same principle can be used for hydrocarbon vapors adsorption on shales has not been validated yet. Thermodynamic potentials are essential indicators of adsorbate-adsorbent interactions, and a suitable adsorption model is the basis of thermodynamics analysis. Therefore, it is urgent to find suitable adsorption models for describing hydrocarbon vapors and carbon dioxide adsorption behavior on shales and to develop a rigorous framework for accurate estimation of the corresponding thermodynamic potentials.

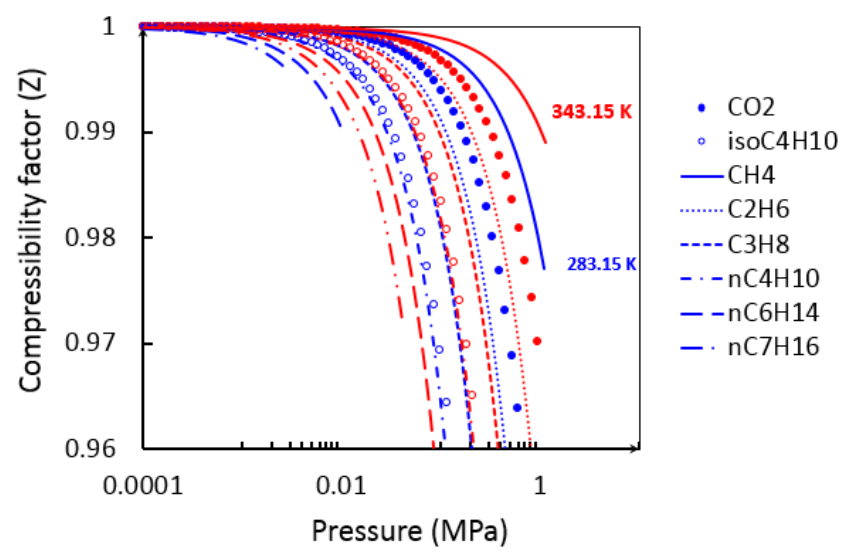

Figure 1 Compressibility factor $(Z)$ of hydrocarbon vapors and carbon dioxide as a function of pressure and temperature; blue color represents $283.15 \mathrm{~K}$ and red color represent $342.15 \mathrm{~K}$. The data is obtained using NIST Reference Fluid Thermodynamic and Transport Properties Database (REFPROP) version 8.0. 
This work first develops a rigorous framework for describing vapor adsorption behavior in porous media based on the classic Langmuir model and the generalized multilayer adsorption model. The framework also allows the direct calculation of the thermodynamic potentials relevant to adsorption by considering non-ideal gas behavior. The developed frame is then tested and validated by measured hydrocarbon vapors (methane, ethane, propane, n-butane, iso-butane, n-heptane and n-hexane) and carbon dioxide adsorption isotherms on four shales. Finally, the adsorption capacity, isosteric enthalpy and entropy as well as some insights for engineering application are discussed in detail. These results provide initial answers for modeling hydrocarbon vapor and $\mathrm{CO} 2$ adsorption isotherms on shales as well as analyzing corresponding thermodynamic potentials.

\section{Theory}

\subsection{Adsorption model}

Adsorption isotherms present the relation, at constant temperature, between adsorption uptake and equilibrium pressure of gas. The experimentally measured adsorption uptake is Gibbs excess adsorption uptake and is always lower than the absolute (true) adsorption uptake (50). The difference between Gibbs excess adsorption uptake and absolute adsorption uptake cannot be ignored for gas adsorption measurement under higher pressures, however, when the equilibrium pressure is relatively low, the Gibbs excess adsorption uptake is identical to the absolute (true) adsorption uptake (17-18,51). Previous studies reveal that hydrocarbon vapors adsorption isotherms on shales and kerogen follow type I and type II style isotherms according to IUPAC recommendations (26, 28, 34-35). Type I and II style isotherms could be described by the monolayer Langmuir model and unrestricted monolayer-multilayer models, respectively.

The classic Langmuir model is the most widely used one because of its simplicity, effectiveness, and the reasonable explanation of its parameters. Langmuir's model and the corresponding surface coverage $\left(\theta^{L}\right)$ can be shown in the following form,

where $n_{a}$ is the adsorption uptake, $n_{0}$ is the maximum adsorption capacity determined by material properties, $P$ is the adsorption pressure, $K_{0}$ is the Langmuir constant which is a function of temperature, $K_{0}=A_{0} e^{\left(-\frac{E_{0}}{R T}\right)}$, where $A_{0}$ is prefactors, $E_{0}$ is the binding energy of the adsorption site, $R$ is universal gas content, $T$ is temperature.

For monolayer-multilayer adsorption, BET (Brunauer-Emmett-Teller) model is the first and basic equation for describing multilayer adsorption behavior in porous media (16). The BET equation is adopted to evaluate the surface area of porous materials according to nitrogen adsorption data (18). In practice, the BET model could only describe adsorption behavior under a relative low pressure (52). In order to extend the application of the multilayer adsorption concept, the BET model was updated as a generalized multilayer adsorption model which is called GAB (Guggenheim-Anderson-de Boer) or Dent's model (53-55). The generalized multilayer adsorption model and the corresponding surface coverage $\left(\theta^{M}\right)$ have the following form, 


$$
\begin{gathered}
n_{a}=\frac{n_{\mathrm{m}} K_{1} P}{\left(1-K_{2} P+K_{1} P\right)} \frac{1}{\left(1-K_{2} P\right)} \\
\theta^{M}=\frac{n_{a}}{n_{\mathrm{m}}}=\frac{K_{1} P}{\left(1-K_{2} P+K_{1} P\right)} \frac{1}{\left(1-K_{2} P\right)}
\end{gathered}
$$

211

212

213

where $n_{a}$ is the adsorption uptake, $n_{m}$ is the monolayer adsorption capacity, $K_{1}$ and $K_{2}$ are related adsorption energies of different adsorption sites as a function of temperature, $K_{1}=A_{1} \exp \left(\frac{-E_{1}}{R T}\right)$ and $K_{2}=A_{2} \exp \left(\frac{-E_{2}}{R T}\right)$, where $A_{1}$ and $A_{2}$ are corresponding prefactors, $E_{1}$ and $E_{2}$ are corresponding binding energy of the adsorption sites, respectively. If one assumes there is only one type of adsorption sites and set $K_{2}=1$, equation (3) is reduced to the classic BET model. It is worth emphasizing the different derivation routes of the BET model and its generalized forms here. Both BET model and GAB model are on the basis that that the adsorbed phase in higher layers is in a condensed states and the heat of adsorption in higher layers is either equal to or less than the heat of liquefaction $(16,53,55)$ while Dent's model is developed from kinetics theory and does not necessarily assume the condensed state of higher adsorbed layers (54). Although these adsorption models are not physically and mathematically equivalent, they do yield essentially equivalent results and interpret the same adsorption process.

\subsection{Isosteric enthalpy}

Based on the Clausius-Clapeyron relationship (42-43), it is known that,

$$
\Delta H_{a d}=\left(\frac{d P}{d T}\right)_{n_{a}} \cdot T \cdot \Delta v
$$

where $\Delta H_{a d}$ is the isosteric enthalpy of adsorption, $\Delta v\left(=\left(v_{g}-v_{a}\right)\right)$ is the volume change of the phase change, $v_{g}$ is the molar volume of the bulk gas phase, $v_{a}$ is the molar volume of the adsorbed phase. If the volume of the adsorbed layer can be ignored $\left(\mathrm{V}_{\mathrm{a}} \rightarrow 0\right)$ and the gas is approximated as an ideal gas $\left(P v_{g_{-} I G}=R T\right.$, the subscript IG denotes ideal gas) under low vapor pressure conditions. Equation (5) can be written as the classic C-C equation as seen in equation (6).

$$
\Delta H_{a d s_{-} I G}=\left(\frac{d P}{d T}\right)_{n_{a}} \frac{R T^{2}}{P}=-R\left[\frac{\partial(\ln P)}{\partial(1 / T)}\right]_{n_{a}}
$$

Equation (6) is historically used to calculate isosteric enthalpy of adsorption for gas (vapor) adsorption from adsorption isotherms. First, a linear relationship $\ln (P)$ and $1 / T$ at a specific adsorption uptake is obtained from multiple adsorption isotherms at different temperatures (47,56-57). Then, the isosteric enthalpy of adsorption is approximated using the slope of the linear relationship. This routinely adopted procedure is tedious and the obtain isosteric enthalpy are not accurate because it is not easy to obtain the linear relationship $\ln (P)$ and $1 / \mathrm{T}$ at a specific adsorption uptake, and the temperature-dependency feature of the isosteric enthalpy of adsorption cannot be revealed either (47). Observing equation (5), it is clear that if the derivative term, $\left(\frac{d P}{d T}\right)_{n}$, is obtained from measured adsorption isotherms, the isosteric enthalpy is readily available (58). 
If one assumes the adsorption process follows the Langmuir equation (eq.1) and applies the Chain Rule for implicit differentiation (58), one form of the derivative term can be obtained as shown in equation (7),

$$
\left(\frac{d P}{d T}\right)_{n_{a}}^{L}=\left(\frac{\partial \theta}{\partial P}\right)_{n_{a}}^{-1}\left(\frac{\partial \theta}{\partial K}\right)_{n_{a}}\left(\frac{\partial K}{\partial T}\right)_{n_{a}}=-\mathrm{E}_{0} \cdot \frac{P}{\mathrm{RT}^{2}}
$$

If one assumes the adsorption process is monolayer-multilayer adsorption following equation 3 , another form of the derivative term can be obtained as shown in equation (8) (46),

$$
\left(\frac{d P}{d T}\right)_{n_{a}}^{M}=\left(\frac{\partial \theta}{\partial P}\right)_{n_{a}}^{-1}\left(\frac{\partial \theta}{\partial K}\right)_{n_{a}}\left(\frac{\partial K}{\partial T}\right)_{n_{a}}=-\frac{\left[E_{1}\left(1-K_{2} P\right)\left(1-K_{2} P\right)+E_{2} K_{2} P\left(2-2 K_{2} P+K_{1} P\right)\right]}{\left(1+K_{1} K_{2} P^{2}-K_{2}^{2} P^{2}\right)} \cdot \frac{P}{R T^{2}}
$$

For dilute gas adsorption, the contribution of the adsorbed phase $\left(\mathrm{V}_{a} \rightarrow 0\right)$ is ignorable. If the real gas law is then applied ( $P v_{\mathrm{g} \_\mathrm{R} G}=\mathrm{ZRT}, \mathrm{Z}$ is the compressibility factor of gas and the subscript $R G$ denotes real gas), two different forms of isosteric enthalpy can be obtained by substituting equations (7- 8 ) into equation (5),

$$
\begin{gathered}
\Delta H_{a d_{-} R G}^{L}=-Z \cdot E_{0} \\
\Delta H_{a d_{-} R G}^{M}=-Z \cdot \frac{\left[E_{1}\left(1-K_{2} P\right)\left(1-K_{2} P\right)+E_{2} K_{2} P\left(2-2 K_{2} P+K_{1} P\right)\right]}{\left(1+K_{1} K_{2} P^{2}-K_{2}^{2} P^{2}\right)}
\end{gathered}
$$

The negative sign means the adsorption process is an exothermic process as shown in equation ( $9 \& 10$ ). Equation (9) indicates that the isosteric enthalpy derived from Langmuir model shows temperature-dependent behavior as the compressibility factor $(Z)$ is temperature-dependent and the binding energy $\left(E_{0}\right)$ remains constant. Equation (10) shows temperature-dependent behavior as the compressibility factor $(Z), K_{1}$ and $K_{2}$ are temperature-dependent.

When gas pressure is extremely low and the gas can be treated ideal gas $(Z=1)$, equation (9) actually represents the heat of adsorption in Henry's law region, also called mean isosteric heat of adsorption,

$$
\Delta H_{a d_{-} I G}^{H}=-E_{0}
$$

Equation (11) is consistent with previous studies that the heat of enthalpy in Henry's law region is independent of temperature and essentially reflects the overall heterogeneous properties of the adsorbent $(47,56)$. The heat of enthalpy in Henry's law region can also be used an index to evaluate the gas adsorption affinity of adsorbents such as coal and shale in the limit of very dilute adsorption $(47,56)$. When thermodynamics analysis is outside the Henry's law region, equations ( 9 or 10 ) have to be employed to consider the non-ideal gas effect.

\subsection{Isosteric entropy}

The isosteric entropy of adsorption $\left(\Delta \mathrm{S}_{a d s}\right)$ and its change with surface coverage reveals the mobility of adsorbed phase. The isosteric entropy of adsorption refers to the change 
278 in entropy due to adsorption at a constant absolute adsorption uptake, which is readily

279 defined by the Clausius-Clapeyron relationship (42-43),

$$
\Delta \mathrm{S}_{a d s}=\left(\frac{d P}{d T}\right)_{n_{a}} \cdot \Delta v
$$

281 Comparing to equation (5), it is clear that $\Delta \mathrm{S}_{a d s}$ is readily available when $\Delta H_{a d s}$ is known 282 as shown in equation (13),

$$
\Delta \mathrm{S}_{a d s}=\frac{\Delta \mathrm{H}_{a d s}}{T}
$$

284 Equation (13) indicates the isostereic entropy is negative and the negative entropy means that the adsorption process is an enthalpy driven process.

\section{Data acquisition}

287

The hydrocarbon vapors and $\mathrm{CO}_{2}$ adsorption in shales are directly retrieved from two publications $(26,34)$. In Pedram's work, hexane (nC6H14) and heptane (nC7H16) vapor adsorption isotherms on Colorado and Utah retorted shales at temperatures of 284.3, 293.7 and $303.2 \mathrm{~K}$. In Zhao's work, CH4, C2H6, C3H8, nC4H10, isoC4H10 and $\mathrm{CO} 2$ sorption on Kimmeridge and Neuquen shales are conducted at temperatures of 308.15, 323.15 and $338.15 \mathrm{~K}$. The adsorption isotherms are measured using gravimetric approach in both works, and detailed information about these tests and shale properties can be found in the original publications $(26,34)$. The pertinent data from these papers are shown in Figure 2, which includes 48 adsorption isotherms with 498 measured data. Since the maximum equilibrium pressure is less than $4000 \mathrm{kPa}$ for all test data, the measured adsorption uptakes are treated as the absolute adsorption uptakes in the following discussions according to Gibbs adsorption concept.
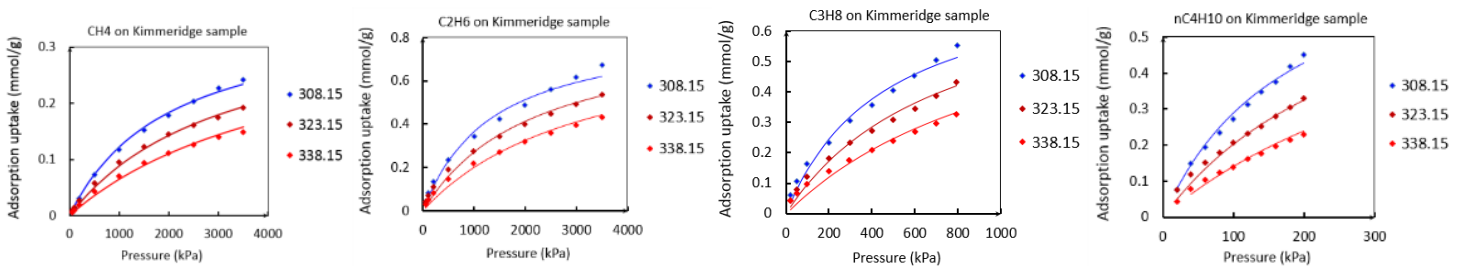

300
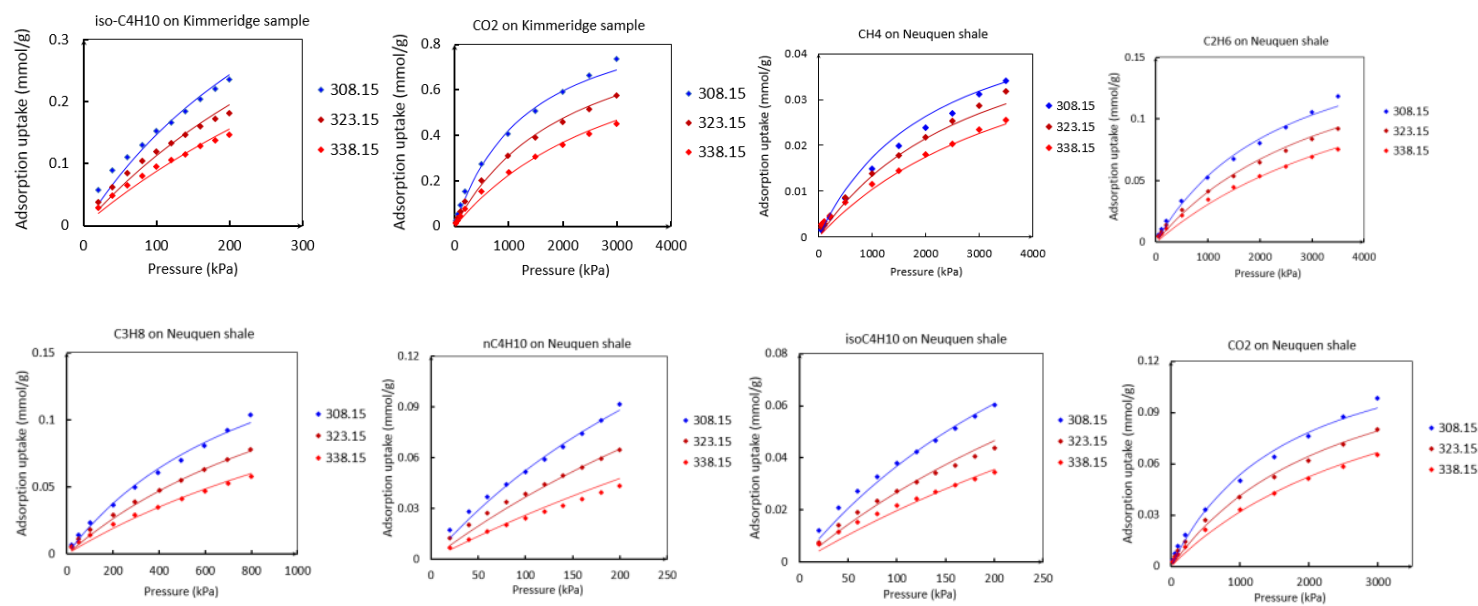

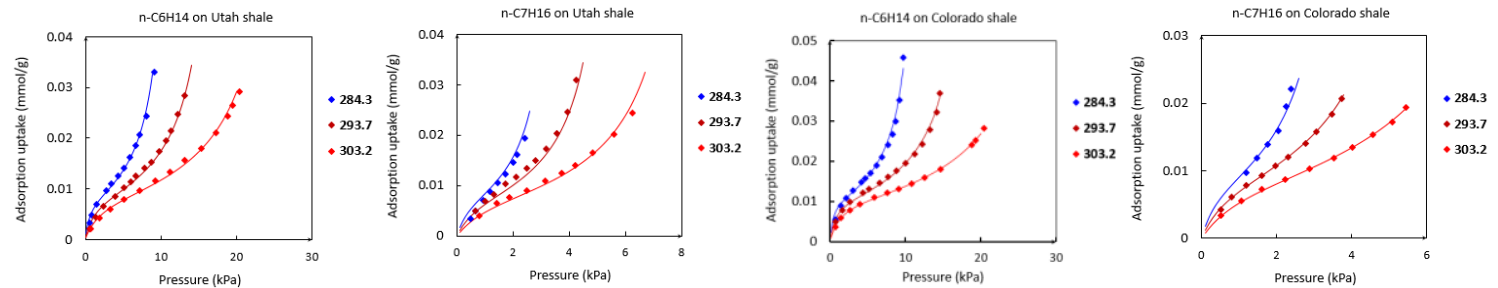

Figure 2 Adsorption isotherms of hydrocarbon vapors and $\mathrm{CO} 2$ on shales (26, 34); the solid points are measured data and solid lines are fitting curves using eq. 1 for Kimmeridge sample and Neuquen shales and eq. 3 for Colorado and Utah retorted shales.

The observed $\mathrm{CH} 4, \mathrm{C} 2 \mathrm{H} 6, \mathrm{C} 3 \mathrm{H} 8, \mathrm{nC} 4 \mathrm{H} 10$, isoC4H10 and $\mathrm{CO} 2$ adsorption isotherms on Neuquen and Kimmeridge shales under different temperatures are fitted simultaneously using equation (1) within the limits of the fitting parameters $\left(0<\mathrm{n}_{0}<10 \mathrm{mmol} / \mathrm{g}, 0 \mathrm{~kJ} / \mathrm{mol}<\right.$ $\left.\mathrm{E}_{0}<100 \mathrm{~kJ} / \mathrm{mol}, 0<\mathrm{A}_{0}\right)$. The observed $\mathrm{nC} 6 \mathrm{H} 14$ and $\mathrm{nC} 7 \mathrm{H} 16$ adsorption isotherms on Colorado and Utah retorted shales under different temperatures are fitted simultaneously using equation (3) within the limits of the fitting parameters $\left(0<\mathrm{n}_{\mathrm{m}}<10 \mathrm{mmol} / \mathrm{g}, 0 \mathrm{~kJ} / \mathrm{mol}\right.$ $<\mathrm{E}_{1}, \mathrm{E}_{2}<100 \mathrm{~kJ} / \mathrm{mol}, 0<\mathrm{A}_{1}, \mathrm{~A}_{2}$ ). The test data is processed using a Universal Global Optimization method of the Auto2Fit software (7D-soft High Technology Inc., China), and the UGO has the capacity to find the global maximal/minimal value of any functions without using the initial start values (46-49). The obtained fitting parameters are shown in Table 1 and RMSE represents the root of mean square error.

Table 1 Fitting parameters for shale samples

\begin{tabular}{|c|c|c|c|c|c|c|c|c|c|c|c|c|c|c|c|}
\hline \multirow{2}{*}{ Sample } & \multirow{2}{*}{ Vapors } & \multicolumn{5}{|c|}{ Langmuir model- Equation 1} & \multirow{2}{*}{ Sample } & \multirow{2}{*}{ Vapors } & \multicolumn{7}{|c|}{ Multilayer model- Equation 3} \\
\hline & & $\mathrm{n}_{0}(\mathrm{mmol} / \mathrm{g})$ & $A_{0}\left(P a^{-1}\right)$ & $\mathrm{E}_{0}(\mathrm{~J} / \mathrm{mol})$ & $\mathbf{R}^{2}$ & RMSE & & & $\mathrm{n}_{\mathrm{m}}(\mathrm{mmol} / \mathrm{g})$ & $A_{1}\left(\mathrm{~Pa}^{-1}\right)$ & $E_{1}(\mathrm{~J} / \mathrm{mol})$ & $\mathrm{A}_{2}\left(\mathrm{~Pa}^{-1}\right)$ & $\mathrm{E}_{2}(\mathrm{~J} / \mathrm{mol})$ & $\mathbf{R}^{2}$ & RMSE \\
\hline \multirow{6}{*}{ Neuquen Shale } & $\mathrm{CH} 4$ & 0.0548 & $2 \mathrm{E}-10$ & \begin{tabular}{|l|}
19843.67 \\
\end{tabular} & 0.9829 & 0.0015 & \multirow{6}{*}{$\begin{array}{l}\text { Colorado } \\
\text { shale }\end{array}$} & \multirow{3}{*}{$\mathrm{nC} 6 \mathrm{H} 14$} & \multirow{3}{*}{0.0103} & \multirow{3}{*}{$6.10 \mathrm{E}-12$} & \multirow{3}{*}{47062.14} & \multirow{3}{*}{$3.43 \mathrm{E}-11$} & \multirow{3}{*}{34598.99} & \multirow{3}{*}{0.9985} & \multirow{3}{*}{0.0005} \\
\hline & $\mathrm{C} 2 \mathrm{H} 6$ & 0.1908 & $1.30 \mathrm{E}-10$ & 20541.44 & 0.9948 & 0.0030 & & & & & & & & & \\
\hline & $\mathrm{C} 3 \mathrm{H} 8$ & 0.2089 & $1.61 \mathrm{E}-10$ & 22644.35 & 0.9937 & 0.0026 & & & & & & & & & \\
\hline & nC4H10 & 0.2083 & $2.86 \mathrm{E}-10$ & 22999.97 & 0.9846 & 0.0028 & & \multirow{3}{*}{$\mathrm{nC} 7 \mathrm{H} 16$} & \multirow{3}{*}{0.0090} & \multirow{3}{*}{$1.71 \mathrm{E}-09$} & \multirow{3}{*}{33412.31} & \multirow{3}{*}{$2.41 \mathrm{E}-10$} & \multirow{3}{*}{32713.09} & \multirow{3}{*}{0.9994} & \multirow{3}{*}{0.0001} \\
\hline & isoC $4 \mathrm{H} 10$ & 0.1751 & $6.58 \mathrm{E}-10$ & \begin{tabular}{|l|}
21282.21 \\
\end{tabular} & 0.9931 & 0.0020 & & & & & & & & & \\
\hline & $\mathrm{CO} 2$ & 0.1456 & $1.52 \mathrm{E}-10$ & \begin{tabular}{|l|}
21144.50 \\
\end{tabular} & 0.9949 & 0.0027 & & & & & & & & & \\
\hline \multirow{6}{*}{ Kimmeridge sample } & $\mathrm{CH} 4$ & 0.3694 & $3.68 \mathrm{E}-11$ & 24353.751 & 0.9965 & 0.0044 & \multirow{6}{*}{ Utah shale } & \multirow{3}{*}{$\mathrm{nC} 6 \mathrm{H} 14$} & \multirow{3}{*}{0.0085} & \multirow{3}{*}{$2.99 \mathrm{E}-11$} & \multirow{3}{*}{41851.66} & \multirow{3}{*}{$1.01 \mathrm{E}-10$} & \multirow{3}{*}{32199.98} & \multirow{3}{*}{0.9969} & \multirow{3}{*}{0.0007} \\
\hline & $\mathrm{C} 2 \mathrm{H} 6$ & 0.8576 & $3.07 \mathrm{E}-11$ & 25874.329 & 0.9905 & 0.0226 & & & & & & & & & \\
\hline & $\mathrm{C} 3 \mathrm{H} 8$ & 0.8093 & $7.23 \mathrm{E}-11$ & 26425.353 & 0.9882 & 0.0194 & & & & & & & & & \\
\hline & $\mathrm{nC} 4 \mathrm{H} 10$ & 0.8244 & $1.05 \mathrm{E}-10$ & 27778.863 & 0.9890 & 0.0120 & & & & & & & & & \\
\hline & isoC4H10 & 0.8000 & $6.61 \mathrm{E}-11$ & 27000.083 & 0.9812 & 0.0174 & & $\mathrm{nC} 7 \mathrm{H} 16$ & 0.0080 & $9.00 \mathrm{E}-10$ & 35000.00 & $3.21 \mathrm{E}-10$ & 32209.10 & 0.9864 & 0.0011 \\
\hline & $\mathrm{CO} 2$ & 0.7533 & $2.95 \mathrm{E}-11$ & 26210.224 & 0.9907 & 0.0213 & & & & & & & & & \\
\hline
\end{tabular}

Once all the fitting parameters are obtained from simulating the observed adsorption isotherms using equations ( 1 or 3 ), the isosteric enthalpy and entropy of adsorption is readily available using equations $(9,10,11 \& 13)$.

\section{Results and Discussion}

\subsection{Adsorption isotherm modeling}

The Langmuir model (eq.1) simulates $\mathrm{CH} 4, \mathrm{C} 2 \mathrm{H} 6, \mathrm{C} 3 \mathrm{H} 8, \mathrm{nC} 4 \mathrm{H} 10$, isoC4H10 and $\mathrm{CO} 2$ adsorption isotherms on Neuquen and Kimmeridge shales very well as shown in Figure 2, and this was also indicated by the fitting parameter $R^{2}$ and RMSE in Table 1 . The maximum adsorption uptake $\left(n_{0}\right)$ of different hydrocarbons has a positive relationship with the molecular mass of hydrocarbon vapors and CO2 on Neuquen and Kimmeridge shales; the higher the molecular mass the higher the maximum adsorption uptake as shown in 
that of Neuquen shale, which can be attributed to the higher total organic content (TOC), nitrogen effective surface area and BJH pore volume. The TOC, nitrogen effective surface area and BJH pore volume of Kimmeridge and Neuquen shale is $51.19 \%, 7 \mathrm{~m}^{2} / \mathrm{g}, 0.038$ $\mathrm{cm}^{3} / \mathrm{g}$ and $3.65 \%, 5.6 \mathrm{~m}^{2} / \mathrm{g}, 0.023 \mathrm{~cm}^{3} / \mathrm{g}$, respectively (34).

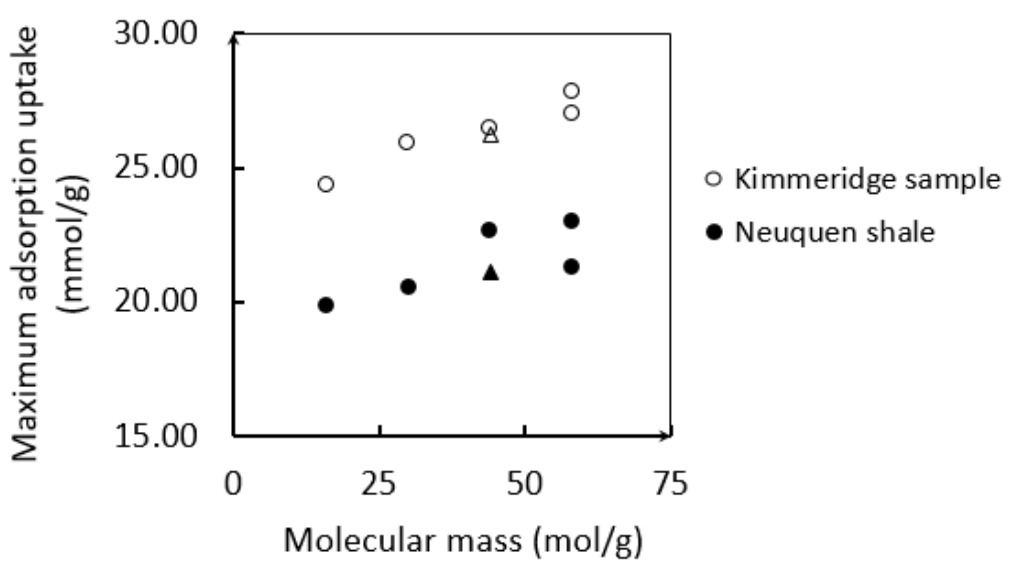

Figure 3 Maximum adsorption capacity of hydrocarbons and carbon dioxide on 338 Neuquen and Kimmeridge shales: triangle represents carbon dioxide, and circle represents hydrocarbons

The multilayer adsorption model (eq.3) has the capacity to describe $\mathrm{nC} 6 \mathrm{H} 14$ and $\mathrm{nC} 7 \mathrm{H} 16$ adsorption behavior on Colorado and Utah retorted shales as well as calculate the monolayer adsorption capacity of each vapor shown in Figure 2. The monolayer adsorption capacity of Colorado shale is higher than that of Utah shale, which is consistent with the nitrogen effective surface area (Figure 4). The measured nitrogen effective surface area of Colorado and Utah shale is $3.4 \mathrm{~m}^{2} / \mathrm{g}$ and $2.1 \mathrm{~m}^{2} / \mathrm{g}$, respectively (26). The monolayer adsorption capacity of $\mathrm{nC} \mathrm{H} 14$ is slightly higher than that of $\mathrm{nC} 7 \mathrm{H} 16$. This could be attributed to the smaller diameter of $\mathrm{nC} 6 \mathrm{H} 14$ compared to $\mathrm{nC} 7 \mathrm{H} 16$, and some local surface area may be inaccessible to larger molecular. The kinetic diameter of $\mathrm{nC} 6 \mathrm{H} 14$ and $\mathrm{nC} 7 \mathrm{H} 16$ is 0.45 and $0.47 \mathrm{~nm}$, respectively (59).

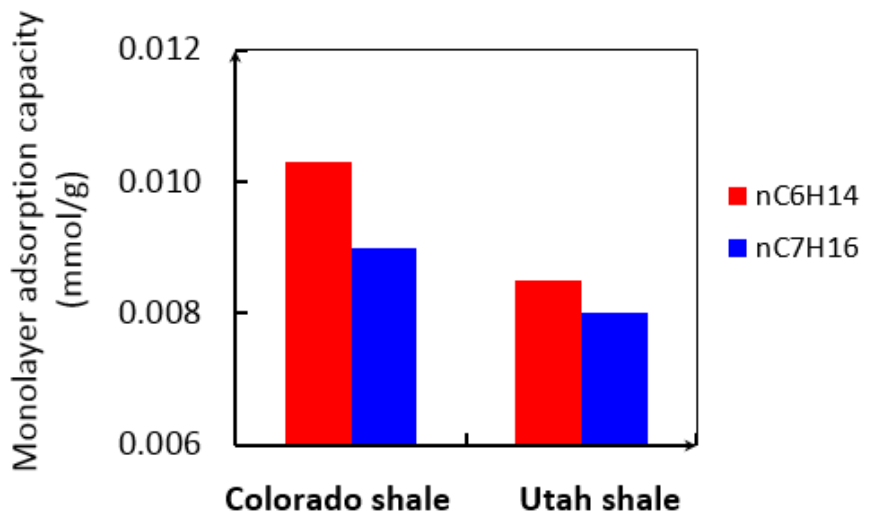


In the following sections, only Kimmeridge shale and Colorado shales are taken as an example to discuss isosteric enthalpy and entropy behavior of hydrocarbon vapors and carbon dioxide during the adsorption process. The isosteric enthalpy and entropy in all figures are presented as absolute/positive values for convenience. The isosteric enthalpy and entropy of hydrocarbon vapors and carbon dioxide on Neuquen and Utah shales are shown in the Supplementary Materials, which is similar to that on Kimmeridge shale and Colorado shales.

\subsection{Isosteric enthalpy}

For $\mathrm{CH} 4, \mathrm{C} 2 \mathrm{H} 6, \mathrm{C} 3 \mathrm{H} 8, \mathrm{nC} 4 \mathrm{H} 10$, isoC4H10 and $\mathrm{CO} 2$ adsorption on Kimmeridge shale, the isosteric enthalpy is less than $30 \mathrm{~kJ} / \mathrm{mole}$, which indicates the adsorption process is physical adsorption (47,56). The isosteric enthalpy also shows adsorption uptake, temperature and gas type dependent behavior (Figure 5). When the adsorption uptake increases, the isosteric enthalpy decreases following a concave-curve trend. The isosteric enthalpy also decreases with increasing temperature. These characteristics can be attributed to the non-ideal behavior of vapors as shown in equation (9), where the isosteric enthalpy is a function of the binding energy $\left(E_{0}\right)$ and gas compressibility factor $(Z)$. The binding energy is constant, and gas compressibility factor $(Z)$ changes with temperature and pressure. For different vapors, the higher the molecular mass, the higher the isosteric enthalpy. As molecular mass of $\mathrm{CO} 2$ and $\mathrm{C} 3 \mathrm{H} 8$ are very close, the isosteric enthalpy are almost the same. The isosteric enthalpy of isoC4H10 is lower than $\mathrm{nC} 4 \mathrm{H} 10$, which is attributed to the polarity difference. The similar behavior has been observed from adsorption uptake where the adsorption uptake of $\mathrm{nC} 4 \mathrm{H} 10$ is higher than isoC $4 \mathrm{H} 10$ under same conditions.
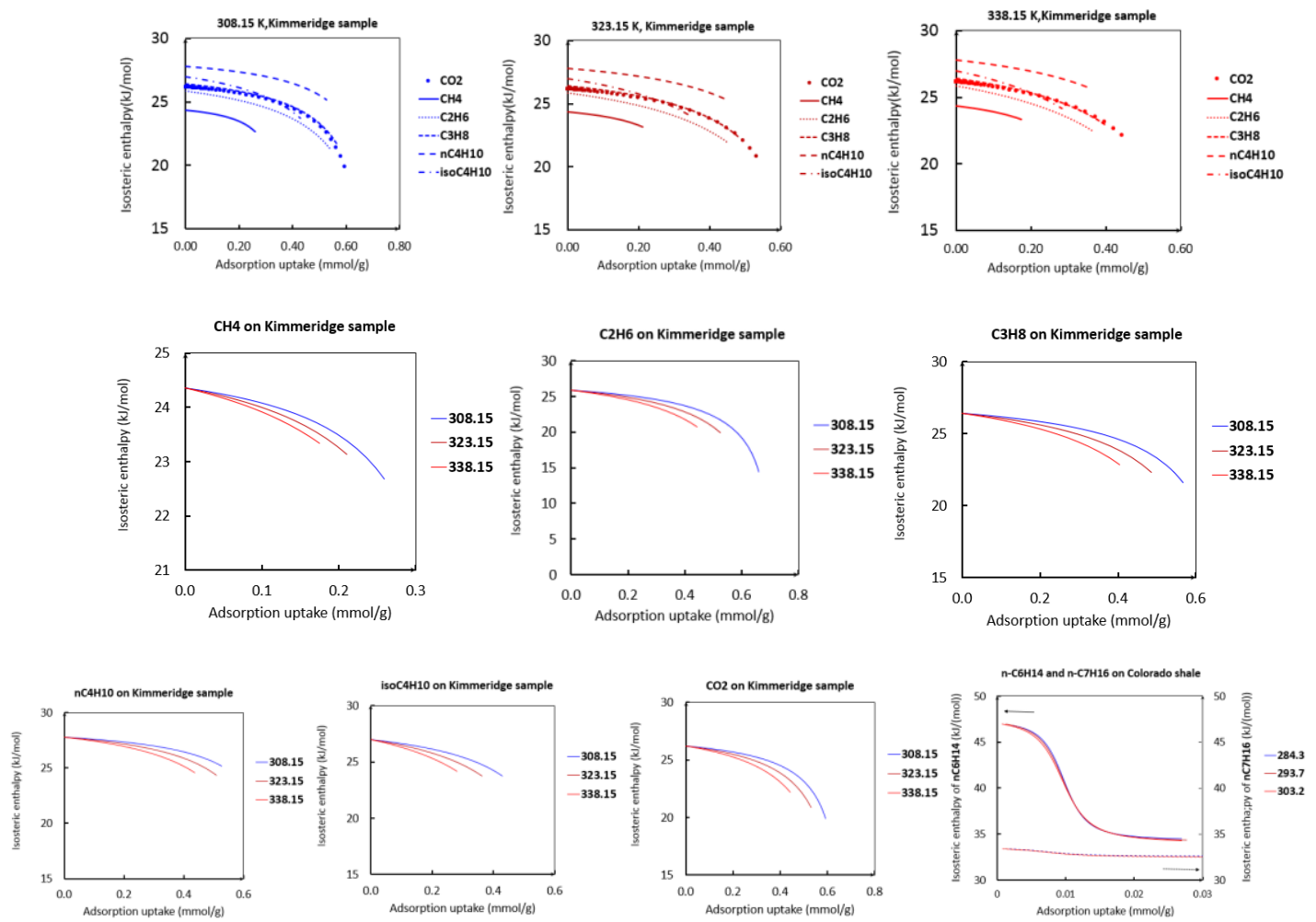
382 Isosteric enthalpy of $\mathrm{nC} 6 \mathrm{H} 14$ and $\mathrm{nC} 7 \mathrm{H} 16$ on Colorado shale ranges from $30 \mathrm{~kJ} / \mathrm{mol}$ to $48 \mathrm{~kJ} / \mathrm{mol}$ indicating a physical adsorption process, and these values are also higher than that of light hydrocarbons and $\mathrm{CO} 2$ on Kimmeridge shales. Figure 5 also indicates that the isosteric enthalpy of $\mathrm{nC} 6 \mathrm{H} 14$ and $\mathrm{nC} 7 \mathrm{H} 16$ sharply decreases following a convex-curve trend and then levels off. This characteristic follows a monolayer, multilayer and capillary condensation behavior of vapors during the adsorption process. When capillary condensation dominates, the isosteric enthalpy almost levels off. High temperature also results in a small shift of the isosteric enthalpy of adsorption, and the temperaturedependent characteristic is readily available. It is also interesting to find that isosteric adsorption of $\mathrm{nC} 6 \mathrm{H} 14$ is much higher than that of $\mathrm{nC} 7 \mathrm{H} 16$, which does not follow the trend that the higher molecular mass the higher the isosteric enthalpy. More experiments are needed to reproduce and clarify this unusual behavior in the future.

\subsection{Isosteric entropy}

For $\mathrm{CH} 4, \mathrm{C} 2 \mathrm{H} 6, \mathrm{C} 3 \mathrm{H} 8, \mathrm{nC} 4 \mathrm{H} 10$, isoC4H10 and $\mathrm{CO} 2$ adsorption on Kimmeridge shale, the isosteric entropy is lower than $0.09 \mathrm{~kJ} /(\mathrm{mol} \mathrm{K})$. Since the process is an enthalpy driven process, the isosteric entropy shows similar behavior of isosteric enthalpy, which depends on adsorption uptake, temperature and gas type. Figure 6 also shows that as the adsorption uptake increases, the isoseric entropy decreases. The reason is that the freedom of gas molecular decreases when free gas molecular becomes adsorbed molecular. When temperature increases, the isosteric entropy also decreases as the adsorbed phase is "less restricted" promoted by higher temperature. It is also clear that the temperature-dependent characteristics is more pronounced for isosteric entropy compared to isosteric enthalpy. For different vapors, the higher the molecular mass, the higher the isosteric entropy. As molecular mass of $\mathrm{CO} 2$ and $\mathrm{C} 3 \mathrm{H} 8$ are identical, the isosteric entropy are almost the same. The isosteric entropy of iso $44 \mathrm{H} 10$ is also lower than $\mathrm{nC} 4 \mathrm{H} 10$. It is worth emphasizing that the decreasing trend of the isoseric entropy does not violate the second law of thermodynamics which states that the entropy of the universe always increases. This is because the adsorption process is not an isolated system. The entropy of the adsorption process does decrease but is more than compensated by the increased entropy of the surroundings due to the heat release.
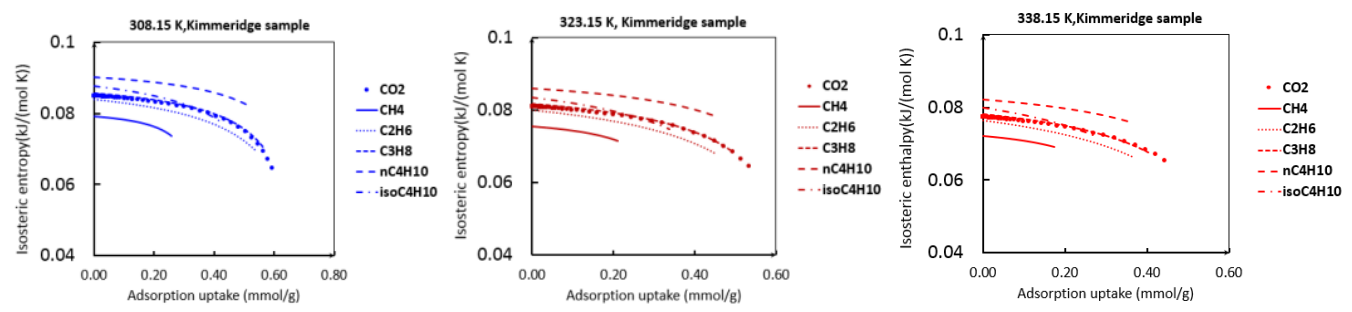

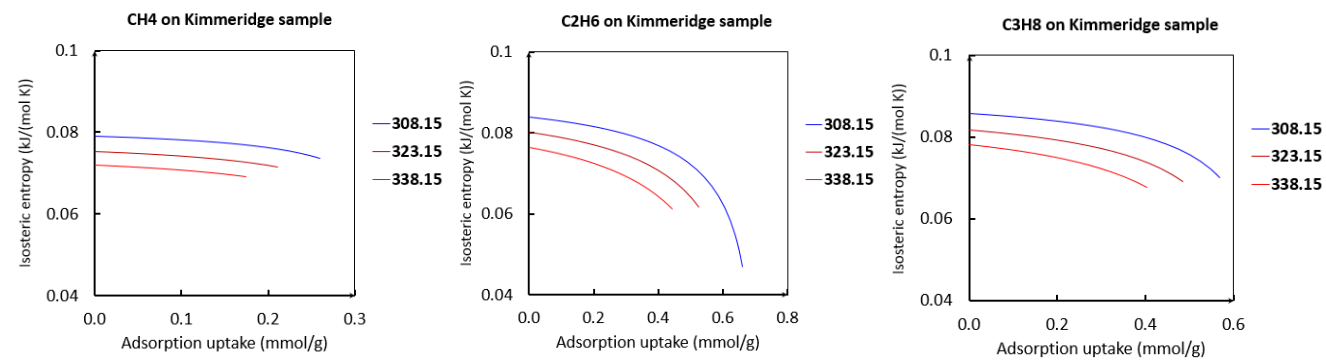

414

415

416

417

418

419

420

421

422

423

424

425

426

427

428

429

430

431

432

433

434

435

436

437

438

439

440

441

442

443
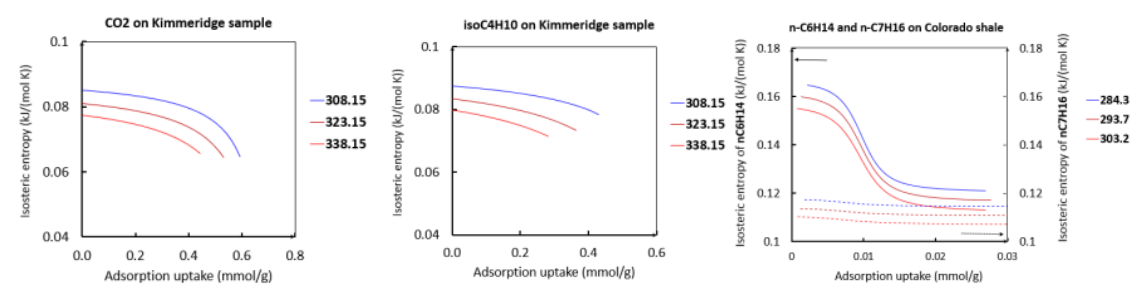

Figure 6 Isosteric entropy of $\mathrm{CH} 4, \mathrm{C} 2 \mathrm{H} 6, \mathrm{C} 3 \mathrm{H} 8, \mathrm{nC} 4 \mathrm{H} 10$, iso $44 \mathrm{H} 10$ and $\mathrm{CO} 2$ adsorption on Kimmeridge shales and $\mathrm{nC} 6 \mathrm{H} 14$ and $\mathrm{nC} 7 \mathrm{H} 16$ adsorption behavior on Colorado shale

Isosteric entropy of $\mathrm{nC} 6 \mathrm{H} 14$ and $\mathrm{nC} 7 \mathrm{H} 16$ on Colorado shale ranges from $0.11 \mathrm{~kJ} / \mathrm{mol}$ to $0.17 \mathrm{~kJ} / \mathrm{mol}$, which is higher than that of light hydrocarbons and $\mathrm{CO} 2$ on Kimmeridge shale. The isosteric entropy sharply decreases and then levels off as the adsorption uptake increases. Considering the monolayer, multilayer and capillary condensation process, the isosteric entropy indicates the freedom of the molecular decreases by the following order: adsorbed molecular of a monolayer, adsorbed molecular of a multilayer, and liquids of pore surface. Higher temperature leads to a lower isosteric entropy as less energy is needed to increase the freedom of molecular. The isosteric entropy of $\mathrm{nC} 6 \mathrm{H} 14$ is much higher than that of $\mathrm{nC} 7 \mathrm{H} 16$. This does not follow the trend that the higher molecular mass the higher the isosteric entropy, and the abnormal behavior needs in-depth study in the future.

\subsection{Insights for enhanced hydrocarbons recovery through $\mathrm{CO} 2$ injection}

It has been evidenced that $\mathrm{CO} 2$ has the capacity to displace $\mathrm{CH} 4$ in coal seams through competitive adsorption as the adsorption affinity of $\mathrm{CO} 2$ on coal is much higher than $\mathrm{CH} 4$, and this lays the foundation for enhanced coalbed methane recovery through $\mathrm{CO} 2$ injection (60). A CO2 huff-and-puff test in shale formations demonstrates injected CO2 can also enhance heavier hydrocarbons recovery including $\mathrm{C} 2 \mathrm{H} 6, \mathrm{C} 3 \mathrm{H} 8$, and $\mathrm{C} 4 \mathrm{H} 10$ (6162). It is worth noting that the heavier hydrocarbons like $\mathrm{C} 5 \mathrm{H} 12, \mathrm{C} 6 \mathrm{H} 14$ and $\mathrm{C} 7 \mathrm{H} 16$ have not been reported in this work because the gas chromatography-mass spectrometry cannot quantify these heavier hydrocarbons (61-63).

Since the isosteric enthalpy in Henry's law region is independent of temperature and reflects the material properties of adsorbent, it may be useful to show the selectivity of hydrocarbons over $\mathrm{CO} 2$. The selectivity of hydrocarbon is defined as the isosteric enthalpy ratio of hydrocarbons to $\mathrm{CO} 2$ in Henry's law region, i.e., $S=\Delta H_{\text {hydrocarbon }}^{H} / \Delta H_{\mathrm{CO} 2}^{H}$. As expected, the selectivity describes the shale affinity of hydrocarbons over $\mathrm{CO} 2$ very well. The higher the molecular mass the higher the selectivity of both shales, and the selectivity 
of $\mathrm{nC} 4 \mathrm{H} 10$ is higher than iso $4 \mathrm{H} 10$, as shown in Figure 7 . It is also found that the selectivity is higher than one for $\mathrm{C} 3 \mathrm{H} 8, \mathrm{nC} 4 \mathrm{H} 10$ and isoC4H10 but is lower than one for $\mathrm{CH} 4$ and $\mathrm{C} 2 \mathrm{H} 6$. This finding coincidently agrees with the fact that the maximum adsorption capacity of $\mathrm{CO} 2$ is higher than $\mathrm{CH} 4$ and $\mathrm{C} 2 \mathrm{H} 6$ but is lower than $\mathrm{C} 3 \mathrm{H} 8, \mathrm{nC} 4 \mathrm{H} 10$ and iso $4 \mathrm{H} 10$, as shown in Table 1 . This means both shales favorably adsorb $\mathrm{C} 3 \mathrm{H} 8, \mathrm{nC} 4 \mathrm{H} 10$ and isoC4H10 compared to $\mathrm{CO} 2$. Even though $\mathrm{CO} 2$ is less competitive compared to heavier hydrocarbon ( $\mathrm{C} 3 \mathrm{H} 8$ and heavier), injected $\mathrm{CO} 2$ still has the capacity to change bulk phase composition of mixture via competitive adsorption especially under high pressure conditions and thus affect the phase envelope of hydrocarbon mixture (38-41). Molecular simulation also indicates that low pressure $\mathrm{CO} 2$ can prevent the capillary condensation of $\mathrm{nC} 4 \mathrm{H} 10$ (37). Furthermore, $\mathrm{CO} 2$ injection has been historically adopted to enhanced oil recovery as $\mathrm{CO} 2$ can dissolve into hydrocarbon liquids and enhance the mobility of these liquids (64-66). The enhanced fluid mobility and phase change of heavier hydrocarbon could finally lead to the enhanced $\mathrm{C} 2 \mathrm{H} 6, \mathrm{C} 3 \mathrm{H} 8$, and $\mathrm{C} 4 \mathrm{H} 10$ in the production flows as observed in shale formations (61-62).

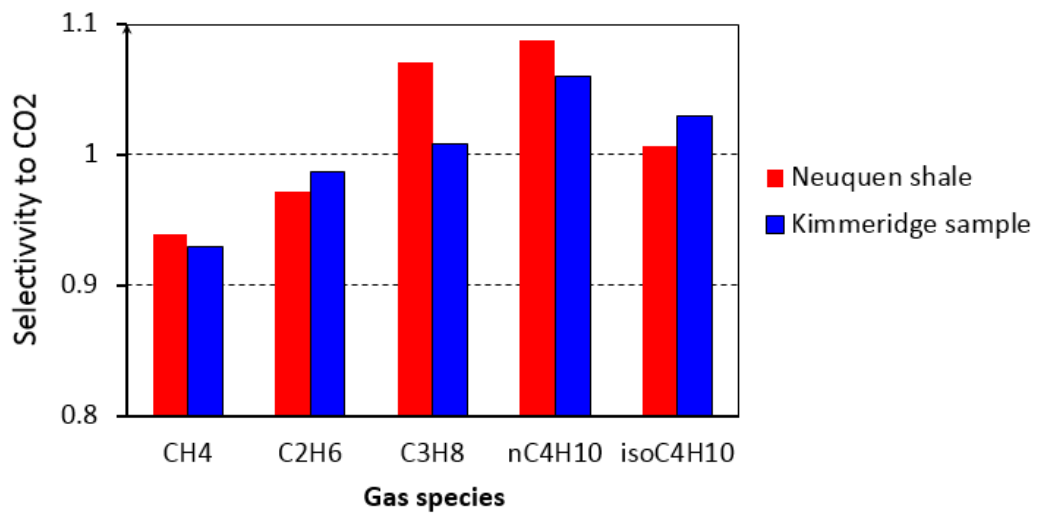

\section{Figure 7 Selectivity of hydrocarbons over carbon dioxide in Henry's law region}

\section{Conclusions}

The Langmuir model and the generalized multilayer adsorption model can be applied over an arbitrary range of pressure at elevated temperatures for the chosen hydrocarbon vapors and carbon dioxide adsorption on shales. An analytical approach for the direct analysis of the thermodynamic quantities of interest from both models has then been validated in this work. Some preliminary conclusions can be obtained,

1. The Langmuir model can describe methane, ethane, propane, n-butane, isobutane and carbon dioxide adsorption isotherms at multiple temperatures via a global fitting approach, respectively. The maximum adsorption capacity of methane, ethane, propane, n-butane, iso-butane and carbon dioxide adsorption on shales positively correlates to the molecular mass of each gas.

2. The generalized multilayer model has the capacity to simulate $n$-hexane and $n$ heptane adsorption behavior accurately under elevated pressures and pressures via a global fitting method for the test results in this work. The monolayer adsorption capacity of $n$-hexane is slightly higher than that of $n$-heptane, and this could be attributed to the smaller diameter of $n$-hexane compared to $n$-heptane, and some local surface area may be inaccessible to larger molecular. 


04

06

3. The isosteric enthalpy and entropy exhibit temperature-dependent as well as adsorption uptake-dependent behavior, which is attributed to the non-ideal gas behavior and temperature-dependent adsorption uptake. Isosteric enthalpy and entropy in general positively correlate to the molecular mass of vapors.

4. Carbon dioxide and propane adsorption on shales shows almost identical behavior in isosteric enthalpy and entropy as their molecular masses are very close. Isosteric enthalpy and entropy of iso-butane is lower than that of n-butane because of the molecule polarity difference.

5. The shale selectivity of propane, n-butane, iso-butane is higher than carbon dioxide while the shale selectivity of methane and ethane is lower than carbon dioxide.

Overall, the proposed framework lays the foundation for investigating hydrocarbon vapors and carbon dioxide adsorption behavior on shales and the associated thermodynamics potentials. This method also allows investigators to analyze how material properties of shales such as compositions, pore structure and surface chemistry affect the surface thermodynamic potentials in the future.

\section{Acknowledgement}

The author would like to thank Professor Abbas Firoozabadi at Yale University for sharing the raw data of hydrocarbon vapors and carbon dioxide sorption on Kimmeridge and Neuquen shales. The project received fundings from the European Union's Horizon 2020 research and innovation programme under the Marie Sklodowska-Curie grant agreement No 793128 (Marie Skłodowska-Curie Individual Fellowship) and the Key Laboratory of Petroleum Resources Research, Institute of Geology and Geophysics, Chinese Academy of Sciences. The author would also like to thank the anonymous reviewers for their comments that helped improve the manuscript.

5

7

08

(1)

11

2

3


517 1. Curtis, J. B. (2002). Fractured shale-gas systems. AAPG bulletin, 86(11), 19211938.

2. GWPC (Ground Water Protection Council) (2009) Modern Shale Gas Development in the United States: A Primer, https://www.energy.gov/fe/downloads/modern-shale-gas-development-unitedstates-primer.

3. US National Energy Technology Laboratory (NETL) (2013) Modern Shale Gas Development in the United States: An Update, https://www.netl.doe.gov/File\%20Library/Research/Oil-Gas/shale-gas-primerupdate-2013.pdf.

4. International Energy Agency (IEA) (2010) Natural Gas Liquids: Supply Outlook 2008-2015, https://webstore.iea.org/natural-gas-liquids-supply-outlook-20082015.

5. International Energy Agency (IEA) (2010) Hydrocarbon Gas Liquids Supply and Demand Short-Term Energy Outlook Model, https://www.eia.gov/outlooks/steo/documentation/steo hgl.pdf.

6. US Department of Energy (DOE) (2018) Natural Gas Liquids Primer-With a Focus on the Appalachian Region, https://www.energy.gov/fe/downloads/natural-gasliquids-primer.

7. Kinder Morgan White Paper, (2018), The Role of Natural Gas Liquids in the American Petrochemical Boom, https://www.kindermorgan.com/content/docs/White Natural Gas Liquids.pdf.

8. Loucks, R. G., Reed, R. M., Ruppel, S. C., \& Jarvie, D. M. (2009). Morphology, genesis, and distribution of nanometer-scale pores in siliceous mudstones of the Mississippian Barnett Shale. Journal of sedimentary research, 79(12), 848-861.

9. Chalmers, G. R., Bustin, R. M., \& Power, I. M. (2012). Characterization of gas shale pore systems by porosimetry, pycnometry, surface area, and field emission scanning electron microscopy/transmission electron microscopy image analyses: Examples from the Barnett, Woodford, Haynesville, Marcellus, and Doig units. AAPG bulletin, 96(6), 1099-1119.

10. Clarkson, C. R., Solano, N., Bustin, R. M., Bustin, A. M. M., Chalmers, G. R. L., He, L., ... \& Blach, T. P. (2013). Pore structure characterization of North American shale gas reservoirs using USANS/SANS, gas adsorption, and mercury intrusion. Fuel, 103, 606-616.

11. Zhou, S., Yan, G., Xue, H., Guo, W., \& Li, X. (2016). 2D and 3D nanopore characterization of gas shale in Longmaxi formation based on FIB-SEM. Marine and Petroleum Geology, 73, 174-180.

12. Leu, L., Georgiadis, A., Blunt, M. J., Busch, A., Bertier, P., Schweinar, K., ... \& Ott, H. (2016). Multiscale description of shale pore systems by scanning SAXS and WAXS microscopy. Energy \& Fuels, 30(12), 10282-10297.

13. Whitson, C. H., \& Sunjerga, S. (2012, January). PVT in liquid-rich shale reservoirs. In SPE Annual Technical Conference and Exhibition. Society of Petroleum Engineers. 
14. Nojabaei, B., Johns, R. T., \& Chu, L. (2013). Effect of capillary pressure on phase behavior in tight rocks and shales. SPE Reservoir Evaluation \& Engineering, 16(03), 281-289.

15. Li, Z., Jin, Z., \& Firoozabadi, A. (2014). Phase behavior and adsorption of pure substances and mixtures and characterization in nanopore structures by density functional theory. SPE Journal, 19(06), 1-096.

16. Brunauer, S., Emmett, P. H., \& Teller, E. (1938). Adsorption of gases in multimolecular layers. Journal of the American chemical society, 60(2), 309-319.

17. Lowell, S., Shields, J. E., Thomas, M. A., \& Thommes, M. (2012). Characterization of porous solids and powders: surface area, pore size and density (Vol. 16). Springer Science \& Business Media.

18. Thommes, M., Kaneko, K., Neimark, A. V., Olivier, J. P., Rodriguez-Reinoso, F., Rouquerol, J., \& Sing, K. S. (2015). Physisorption of gases, with special reference to the evaluation of surface area and pore size distribution (IUPAC Technical Report). Pure and Applied Chemistry, 87(9-10), 1051-1069.

19. Dubinin, M. M., \& Astakhov, V. A. (1971). Development of the concepts of volume filling of micropores in the adsorption of gases and vapors by microporous adsorbents. Bulletin of the Academy of Sciences of the USSR, Division of chemical science, 20(1), 3-7.

20. Evans, R. (1990). Fluids adsorbed in narrow pores: phase equilibria and structure. Journal of Physics: Condensed Matter, 2(46), 8989.

21. Li, J. R., Kuppler, R. J., \& Zhou, H. C. (2009). Selective gas adsorption and separation in metal-organic frameworks. Chemical Society Reviews, 38(5), 14771504.

22. Schappert, K. B. (2014). Confinement effects in nanopores: elastic properties, phase transitions, and sorption-induced deformation. Doctoral Thesis. http://dx.doi.org/10.22028/D291-22969.

23. Gor, G. Y., Huber, P., \& Bernstein, N. (2017). Adsorption-induced deformation of nanoporous materials-A review. Applied Physics Reviews, 4(1), 011303.

24. Zhang, J., Chen, J. H., \& Edwards, C. (2012a). Lab NMR study on adsorption/condensation of hydrocarbon in smectite clay. In SPE/EAGE European Unconventional Resources Conference \& Exhibition-From Potential to Production, Vienna, Austria, 20-22.

25. Zhang, J., Chen, J. H., Jin, G., Quinn, T., \& Frost, E. (2012b) Butane condensation in kerogen pores and in smectite clay: NMR relaxation and comparison in lab study. SCA2012-46, http://www.jgmaas.com/SCA/2012/SCA2012-46.pdf.

26. Pedram, E. O., \& Hines, A. L. (1984). Vapor adsorption of $n$-hexane and $n$-heptane on retorted oil shales. Industrial \& Engineering Chemistry Process Design and Development, 23(4), 728-732.

27. Dmitrievskii, A. N., Pribylov, A. A., Skibitskaya, N. A., Kubyshkin, A. P., \& Shpirt, M. Y. (2006). Sorption of butane, propane, ethane, methane, and carbon dioxide on asphaltene. Russian journal of physical chemistry, 80(7), 1099-1104.

28. Pribylov, A. A., \& Skibitskaya, N. A. (2014). Sorption of methane, ethane, propane, butane, carbon dioxide, and nitrogen on kerogen. Russian Journal of Physical Chemistry A, 88(6), 1028-1036. 
29. Zandavi, S. H., \& Ward, C. A. (2015). Characterization of the pore structure and surface properties of shale using the zeta adsorption isotherm approach. Energy \& Fuels, 29(5), 3004-3010.

30. Kumar, S., Prasad, M., \& Pini, R. (2015). Selective adsorptives to study pore structure and wetting behavior of self-resourcing shales. In SPWLA 56th Annual Logging Symposium. Society of Petrophysicists and Well-Log Analysts.

31. Orzechowska-Zięba, A., \& Nodzeński, A. (2017). Energetic effects of adsorption of C6-C8 hydrocarbons on hard coal samples of different metamorphism. In E3S Web of Conferences (Vol. 14, p. 02027). EDP Sciences.

32. Zhang, J., Lu, S., Li, J., Zhang, P., Xue, H., Zhao, X., \& Xie, L. (2017). Adsorption Properties of Hydrocarbons ( $n$-Decane, Methyl Cyclohexane and Toluene) on Clay Minerals: An Experimental Study. Energies, 10(10), 1586.

33. Li, J., Lu, S., Xie, L., Zhang, J., Xue, H., Zhang, P., \& Tian, S. (2017). Modeling of hydrocarbon adsorption on continental oil shale: A case study on n-alkane. Fuel, 206, 603-613.

34. Zhao, H., Lai, Z., \& Firoozabadi, A. (2017). Sorption hysteresis of light hydrocarbons and carbon dioxide in shale and kerogen. Scientific reports, $7(1)$, 16209.

35. Zhao, H., Wu, T., \& Firoozabadi, A. (2018). High pressure sorption of various hydrocarbons and carbon dioxide in Kimmeridge Blackstone and isolated kerogen. Fuel, 224, 412-423.

36. Li, Z., Jin, Z., \& Firoozabadi, A. (2014). Phase behavior and adsorption of pure substances and mixtures and characterization in nanopore structures by density functional theory. SPE Journal, 19(06), 1096-1109.

37. Jin, Z., \& Firoozabadi, A. (2016). Phase behavior and flow in shale nanopores from molecular simulations. Fluid Phase Equilibria, 430, 156-168.

38. Jin, Z. (2018). Bubble/dew point and hysteresis of hydrocarbons in nanopores from molecular perspective. Fluid Phase Equilibria, 458, 177-185.

39. Luo, S., Lutkenhaus, J. L., \& Nasrabadi, H. (2016a). Use of differential scanning calorimetry to study phase behavior of hydrocarbon mixtures in nano-scale porous media. Journal of Petroleum Science and Engineering. 163,731-738.

40. Luo, S., Lutkenhaus, J. L., \& Nasrabadi, H. (2016b). Confinement-induced supercriticality and phase equilibria of hydrocarbons in nanopores. Langmuir, 32(44), 11506-11513.

41. Sandoval, D. R., Yan, W., Michelsen, M. L., \& Stenby, E. H. (2018). Influence of Adsorption and Capillary Pressure on Phase Equilibria inside Shale Reservoirs. Energy \& Fuels, 32(3), 2819-2833.

42. Clapeyron, M. C. (1834). "Mémoire sur la puissance motrice de la chaleur". Journal de l'École polytechnique (in French). 23: 153-190. ark:/12148/bpt6k4336791/f157.

43. Clausius, R. (1850). "Ueber die bewegende Kraft der Wärme und die Gesetze, welche sich daraus für die Wärmelehre selbst ableiten lassen" [On the motive power of heat and the laws which can be deduced therefrom regarding the theory of heat]. Annalen der Physik (in German). 155: 500-524.

44. Pan, H., Ritter, J. A., \& Balbuena, P. B. (1998). Examination of the approximations used in determining the isosteric heat of adsorption from the Clausius-Clapeyron equation. Langmuir, 14(21), 6323-6327. 
45. Chakraborty, A., Saha, B. B., Koyama, S., \& Ng, K. C. (2006). On the thermodynamic modeling of the isosteric heat of adsorption and comparison with experiments. Applied physics letters, 89(17), 171901.

46. Tang, X., Ripepi, N., Valentine, K. A., Keles, C., Long, T., \& Gonciaruk, A. (2017a). Water vapor sorption on Marcellus shale: measurement, modeling and thermodynamic analysis. Fuel, 209, 606-614.

47. Tang, X., Ripepi, N., Stadie, N. P., \& Yu, L. (2017b). Thermodynamic analysis of high pressure methane adsorption in Longmaxi shale. Fuel, 193, 411-418.

48. Tang, X., \& Ripepi, N. (2017c). High pressure supercritical carbon dioxide adsorption in coal: Adsorption model and thermodynamic characteristics. Journal of CO2 Utilization, 18, 189-197.

49. Wang, Z., \& Tang, X. (2018). New Insights from Supercritical Methane Adsorption in Coal: Gas Resource Estimation, Thermodynamics, and Engineering Application. Energy \& Fuels, 32(4), 5001-5009.

50. Gibbs, J. W. (1878). On the equilibrium of heterogeneous substances. American Journal of Science, (96), 441-458.

51. Tang, X., Ripepi, N., Luxbacher, K., \& Pitcher, E. (2017d). Adsorption Models for Methane in Shales: Review, Comparison, and Application. Energy \& Fuels, 31(10), 10787-10801.

52. Kozłowska, A., \& Kozłowski, R. (2012). Analysis of water adsorption by wood using the Guggenheim-Anderson-de Boer equation. European Journal of Wood and Wood Products, 70(4), 445-451.

53. Dole, M. (1948). Statistical thermodynamics of the sorption of vapors by solids. The Journal of Chemical Physics, 16(1), 25-30.

54. Dent, R. W. (1977). A multilayer theory for gas sorption part I: sorption of a single gas. Textile Research Journal, 47(2), 145-152.

55. Anderson, R. B. (1946). Modifications of the Brunauer, Emmett and Teller equation1. Journal of the American Chemical Society, 68(4), 686-691.

56. Tang, X., Wang, Z., Ripepi, N., Kang, B., \& Yue, G. (2015). Adsorption affinity of different types of coal: mean isosteric heat of adsorption. Energy \& Fuels, 29(6), 3609-3615.

57. Wang, Z., Tang, X., Yue, G., Kang, B., Xie, C., \& Li, X. (2015). Physical simulation of temperature influence on methane sorption and kinetics in coal: Benefits of temperature under 273.15 K. Fuel, 158, 207-216.

58. Mertens, F. O. (2009). Determination of absolute adsorption in highly ordered porous media. Surface Science, 603(10), 1979-1984.

59. Yu, Y. X., \& Gao, G. H. (2000). Lennard-Jones chain model for self-diffusion of n-alkanes. International journal of thermophysics, 21(1), 57-70.

60. White, C. M., Smith, D. H., Jones, K. L., Goodman, A. L., Jikich, S. A., LaCount, R. B., ... \& Schroeder, K. T. (2005). Sequestration of carbon dioxide in coal with enhanced coalbed methane recovery a review. Energy \& Fuels, 19(3), 659-724.

61. Louk, K., Ripepi, N., Luxbacher, K., Gilliland, E., Tang, X., Keles, C., ... \& Michael, K. (2017). Monitoring CO 2 storage and enhanced gas recovery in unconventional shale reservoirs: Results from the Morgan County, Tennessee injection test. Journal of Natural Gas Science and Engineering, 45, 11-25.

62. Karmis, Michael, Ripepi, Nino, Gilliland, Ellen, Louk, Andrew, Tang, Xu, Keles, Cigdem, Schlosser, Charles, Diminick, Ed, McClure, Michael, Hill, Gerald, and Hill, 
Brian. Central Appalachian Basin Unconventional (Coal/Organic Shale) Reservoir Small Scale CO2 Injection Test. United States: N. p., 2018. Web. doi:10.2172/1439921.

63. Ripepi, N., Louk, K., Amante, J., Schlosser, C., Tang, X., \& Gilliland, E. (2017). Determining coalbed methane production and composition from individual stacked coal seams in a multi-zone completed gas well. Energies, 10(10), 1533.

64. Fogg, P. G. (Ed.). (1992). Carbon Dioxide in non-aqueous solvents at pressures less than 200 kPa. Solubility Data Series; Pergamon Press: Elmsford, NY, 1992; Vol. 50.

65. Ghedan, S. (2009, October). Global laboratory experience of CO2-EOR flooding. In SPE/EAGE reservoir characterization \& simulation conference. https://doi.org/10.2118/125581-MS.

66. NETL, 2010, Carbon Dioxide Enhanced Oil Recovery, Untapped Domestic Energy Supply and Long Term Carbon Storage Solution, https://www.netl.doe.gov/file\%20library/research/oil-gas/CO2 EOR Primer.pdf. 
744
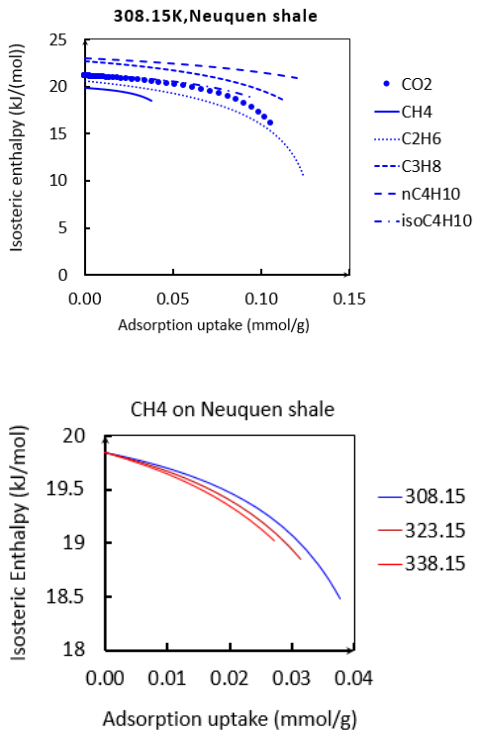

748

Xu Tang ${ }^{1,2}$ 4.

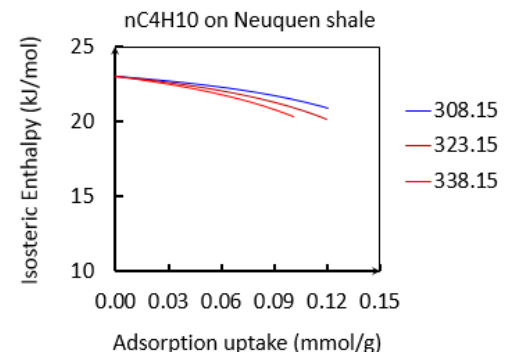
shale

\section{Surface Thermodynamics of Hydrocarbon Vapors and Carbon Dioxide Adsorption on} Shales

\section{Supplemental Materials}

1 School of Chemistry, University of Nottingham, Nottingham, NG7 2RD, UK;

2 Key Laboratory of Petroleum Resources Research, Institute of Geology and Geophysics, Chinese Academy of Sciences, Beijing 100029, China

Corresponding author: Xu Tang (xutang2050@outlook.com)

Supplemental Materials show the isosteric enthalpy and entropy of hydrocarbon vapors and carbon dioxide adsorption on Neuquen and Utah shales including Figures S-1 to S-
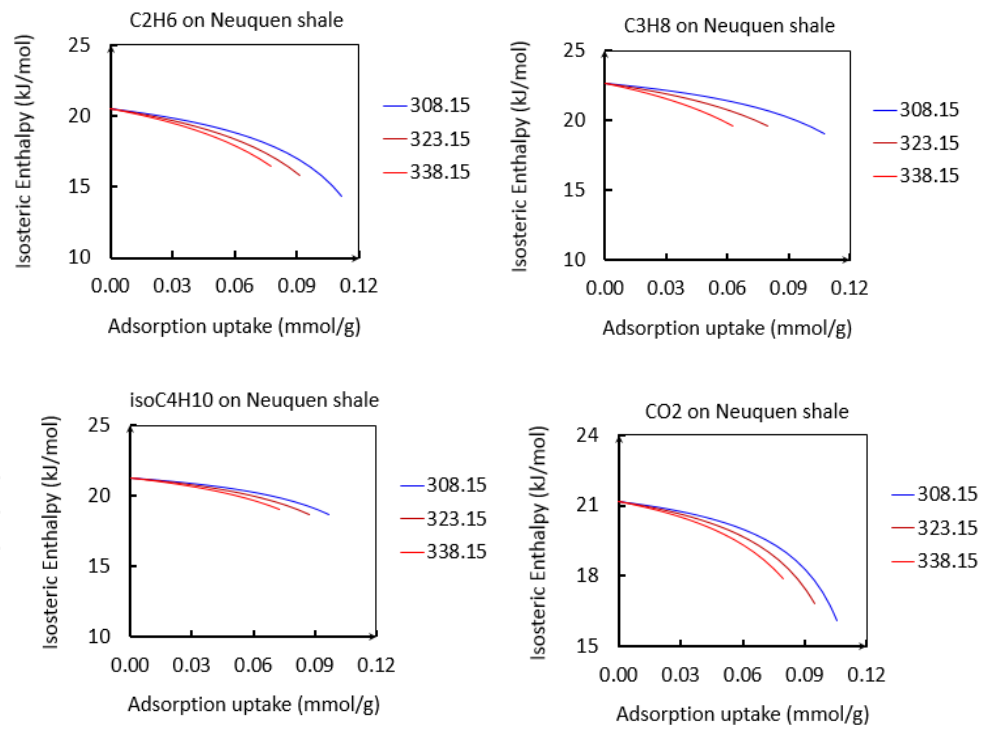

Figure S-1 Isosteric enthalpy of hydrcarbons and carbon dioxide on Neuquen 

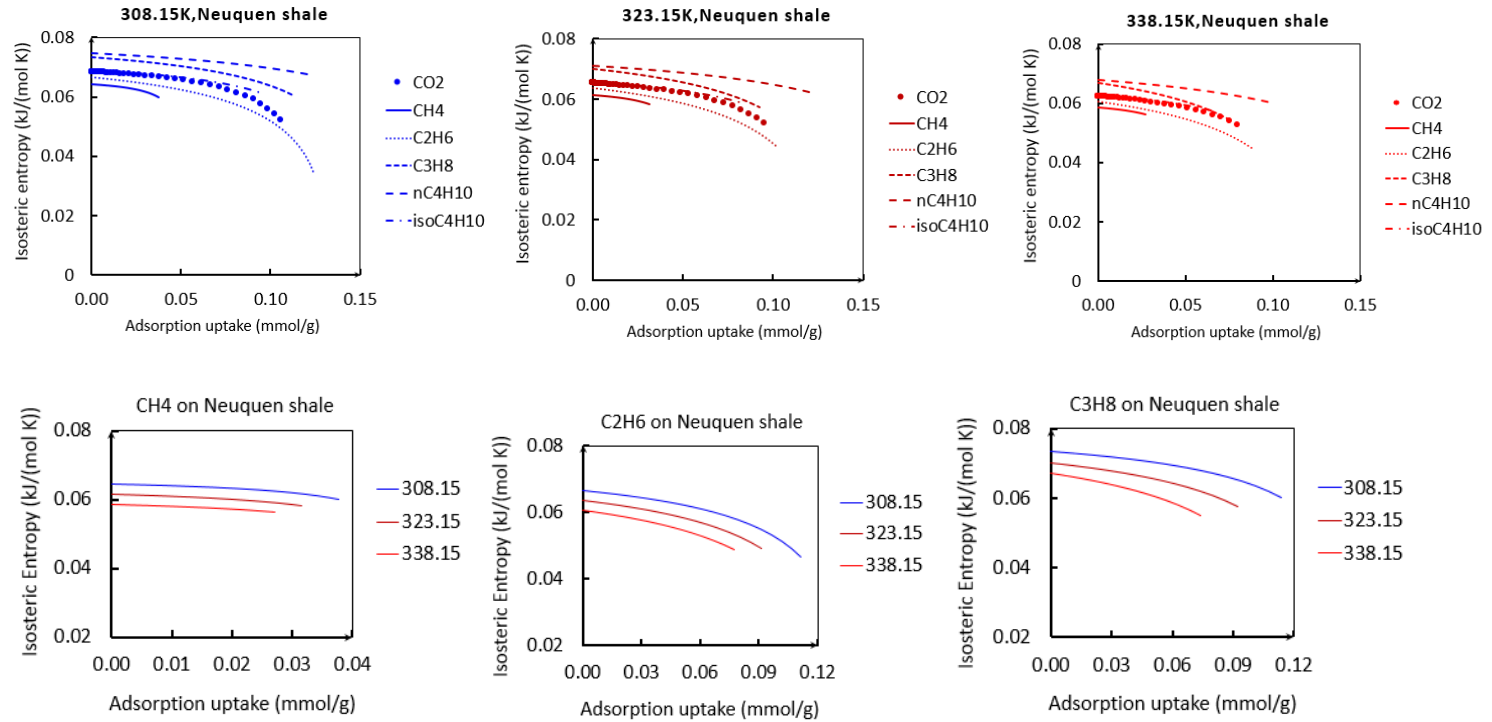

753
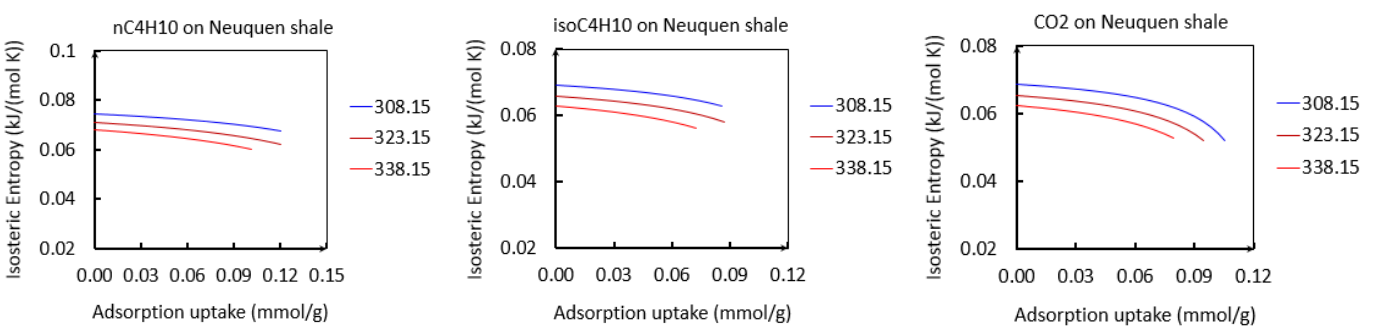

Figure S-2 Isosteric entropy of hydrcarbons and carbon dioxide on Neuquen 756 shales
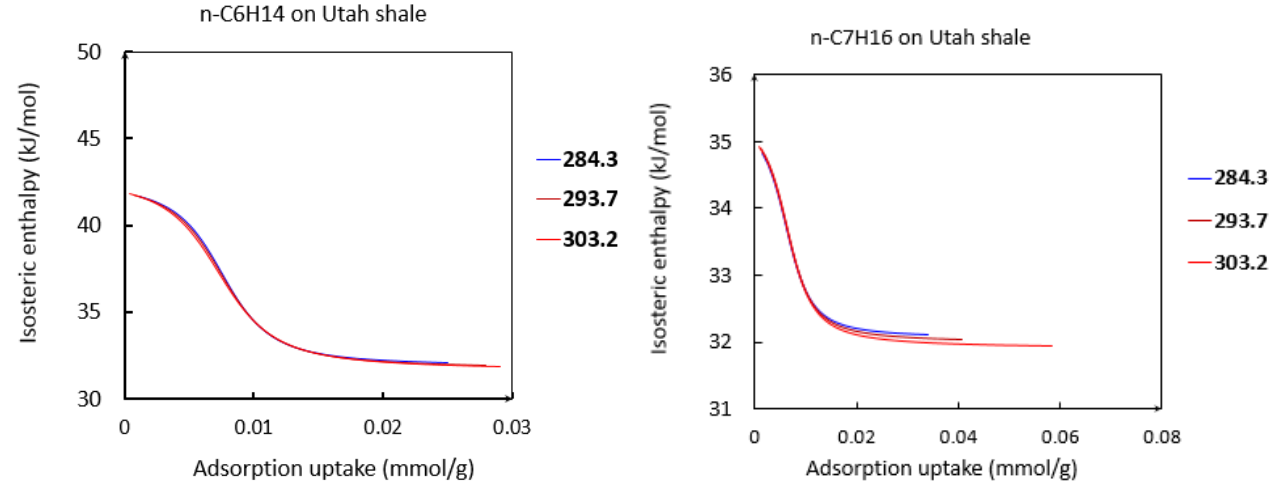

758 Figure S-3 Isosteric enthalpy of nC6H14 and nC7H16 on Utah shale 

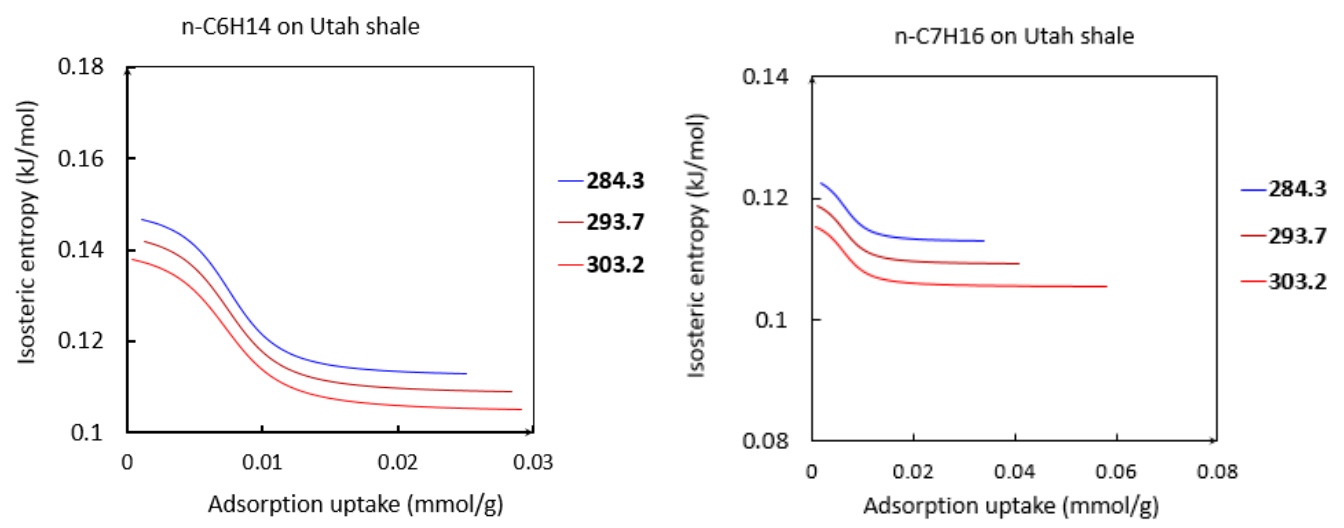

759

Figure S-4 Isosteric entropy of $\mathrm{nC} 6 \mathrm{H} 14$ and $\mathrm{nC} 7 \mathrm{H} 16$ on Utah shale

761

762

763 